\title{
METHOD TO SELECT THE COUNTRIES AND SCENARIOS MORE APPROPRIATE FOR THE DEPLOYMENT OF SMR
}

\author{
Giorgio Locatelli \\ University of Lincoln \\ Lincoln School of Engineering \\ Brayford Pool - Lincoln LN6 7TS \\ United Kingdom \\ Phone;+441522837946 \\ glocatelli@lincoln.ac.uk
}

\author{
Mauro Mancini \\ Politecnico di Milano \\ Dep. of Management, \\ Economics \& Industrial Eng. \\ Via Lambruschini 4/B Milano - \\ Italy \\ Phone;+390223994057 \\ mauro.mancini@polimi.it
}

\author{
Pietro Belloni \\ Politecnico di Milano \\ Dep. of Management, \\ Economics \& Industrial Eng. \\ Via Lambruschini 4/B Milano - \\ Italy \\ Phone;+393472709264 \\ pietro.belloni1@gmail.com
}

\section{ABSTRACT}

The evolution of nuclear technologies has led to the development of a large number of reactor designs. In particular there is significant and growing interest towards Small Modular Reactors (SMRs), i.e. nuclear reactor of a size between 40MWe and 700 MWe. Several heterogeneous countries are potentially interested in their deployment and approximately twenty advanced SMR designs are under development all over the world. However, both the market dimensions for SMRs and where they may be deployed remain unclear. This paper presents a method for the identification of countries which could be interested in the construction of SMRs and which factors foster their deployment. The presented method, grounded on a comprehensive literature review, is composed of three screenings and comprises the strategic consequences of the Fukushima accident. The first screening selects all the countries of the world that the International Atomic Energy Agency (IAEA) and World Nuclear Association (WNA) indicate as possible market for nuclear reactor in general. The second screening selects countries based on their potential interest in SMR development in the short to medium term. The third screening identifies countries where SMRs are a particularly suitable choice. To perform this last "scenario based" selection the strengths and weakness of the SMRs have been analyzed to define their strategic match with the potential countries. The findings of this investigation reveal the strategic factors promoting the deployment of SMR and provide the basis for a ranking of countries in which these factors could create the market for SMR.

\section{INTRODUCTION}

Nuclear energy is considered as one of the most sustainable solutions to satisfy in the middle term the growing demand of electricity [1], [2]. Table 1 shows nuclear electricity production in 2008 and 2010 and the estimates of nuclear electricity generation capacity in 2020 and 2030 with a low and high scenario.

\begin{tabular}{|c|c|c|c|c|c|c|}
\hline \multirow{2}{*}{ Region } & \multirow{2}{*}{$\mathbf{2 0 0 8}$} & \multirow{2}{*}{$\mathbf{2 0 1 0}$} & \multicolumn{2}{|c|}{$\mathbf{2 0 2 0}$} & \multicolumn{2}{|c|}{$\mathbf{2 0 3 0}$} \\
\cline { 4 - 7 } & & & Low & High & Low & High \\
\hline North America & 113.3 & 114.5 & 126 & 130 & 127 & 168 \\
\hline Latin America & 4 & 4 & 7 & 8 & 11 & 23 \\
\hline Western Europe & 122.5 & 121 & 90 & 131 & 82 & 158 \\
\hline Eastern Europe & 47.5 & 47 & 68 & 81 & 83 & 121 \\
\hline Africa & 1.8 & 1.8 & 2.8 & 4.1 & 6.1 & 17 \\
\hline $\begin{array}{c}\text { Middle East Asia } \\
\text { and South Asia }\end{array}$ & 4.2 & 9.1 & 13 & 24 & 20 & 56 \\
\hline Far East & 78.3 & 79.8 & 138 & 165 & 183 & 259 \\
\hline Oceania & - & - & - & - & 0 & 5.2 \\
\hline World total & 371.6 & 377.2 & 445 & 543 & 511 & 807 \\
\hline
\end{tabular}

Table 1 Nuclear electricity generating capacity [GWe] [3]

The evolution of nuclear technologies provides a greater variety of technological choices including many options on the size of nuclear reactors. Nowadays a significant interest towards SMRs is growing in several countries, from those economically and industrially developed to those isolated and in remote areas [4]. The IAEA defines a "small" reactor having electrical output less than $300 \mathrm{MWe}$ and a "medium" reactor as one having output between 300 and $700 \mathrm{MWe}$. More often, the two sizes are combined into the common term "Small and Medium Reactor" or somehow "Small Modular 
Reactors". From now on SMR represents a nuclear reactor with electrical output less than 700 MWe.

About 20 advanced SMRs designs have been completed with licensing status in progress [5]. One of the reasons to foster the deployment of SMR is the smaller dimension and intrinsic more simple design respect to Large Reactors (LR). In particular SMR seems an attractive solution after the poor performance in building LR in Europe [6] [7]. However it is still unclear the market dimension for SMRs and where more likely they will be deployed. This paper provides a method to select and investigate which countries could be interested in the construction of SMRs and which factors foster their deployment.

\section{METHODOLOGY}

The selection of countries suitable for SMR is obtained with three successive screenings.

In the first screening, all the countries of the world have been analysed to select those considered as a market for Nuclear Power Plant (NPP). This selection is based on documents provided by the International Atomic Energy Agency (IAEA) and the (World Nuclear Association) WNA. These two agencies update monthly their database and their reports about all the countries involved and interested in nuclear power.

In the second screening, we focus the analysis investigating the countries interested in nuclear power. The analysis is based on information coming from the industrial and academic literature and qualitative considerations. At this point the following typology of countries will be discarded: those where the SMRs do not coincide with the country's energy policies and are not willing to invest in SMRs. The willingness to invest should be focused in a short to medium term.

In the third screening, the goal is to select the countries where SMRs are more profitable and the investment sustainable. This goal is accomplished in two main steps: (1) investigating the strengths of the SMRs to define the strategic factors and (2) comparing the possible scenarios that can be achieved in the remaining countries. The strategic scenario will consider:

- economic factors;

- external factors;

- co-generation applications.

This research is also aimed at defining the best configuration of the plant that gives more benefits. In this type of methodology an essential role is given by the choice of filters used in the three stages for the countries selection.

Figure 1 shows the path followed by the third screening. This approach simplifies the countries selection, which is a complex task due to the large number of factors to be considered and their quantitative and qualitative nature. The final result is the ranking of countries selected in step 3 .

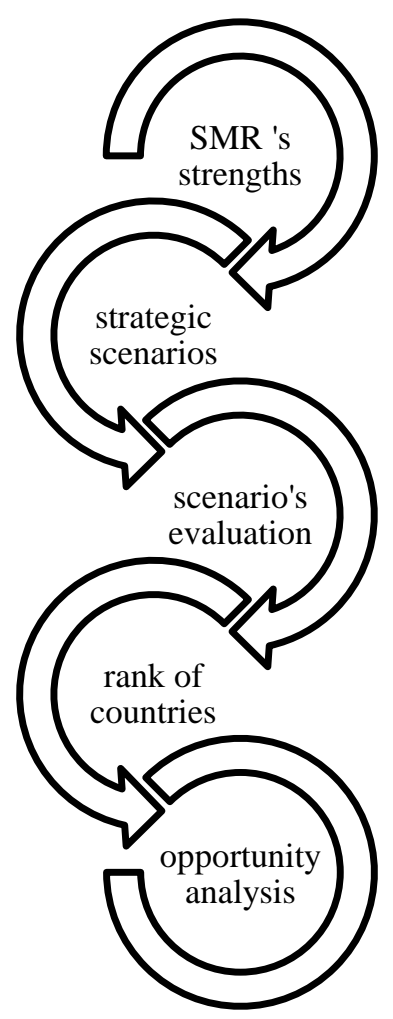

Figure 1 Cycle of methodology adopted in third stage

\section{SELECTION}

The analysis is grounded on the information provided and developed by [8] and [9] primarily for those countries aimed to be newcomer, and secondarily for those that already use nuclear technology. This research cannot overlook the importance of Fukushima accident. This event has led many countries to review their energy strategy about nuclear power generation and prompted an immediate review of the nuclear energy safety in most countries with nuclear programmes. Fukushima has reopened the global discussion about the future of nuclear power. We included further analysis for those countries that in the pre-Fukushima period had intention to invest in nuclear power focusing in SMRs and for those countries whose information obtained from IAEA and WNA have not been updated to post-Fukushima yet.

\section{First selection}

Of the 195 sovereign States internationally recognized (including Vatican City and Taiwan) [10], 84 countries, divided into 53 emerging nuclear energy countries and 31 nuclear countries have been considered.

\section{Emerging nuclear energy Countries}

According to [11] nuclear power is under consideration in 53 countries that do not currently have commercial nuclear reactors. The complete list is:

- In Europe: Albania, Serbia, Croatia, Portugal, Norway, Poland, Belarus, Estonia, Latvia, Ireland, Turkey. 
- In the Middle East and North Africa: UAE, Saudi Arabia, Qatar, Oman, Kuwait, Yemen, Israel, Syria, Jordan, Egypt, Tunisia, Libya, Algeria, Morocco, Sudan.

- In West, central and southern Africa: Nigeria, Ghana, Senegal, Kenya, Uganda, Namibia.

- In central and southern Asia: Azerbaijan, Georgia, Kazakhstan, Mongolia, Bangladesh, Sri Lanka.

- In Southeast Asia: Indonesia, Philippines, Vietnam, Thailand, Malaysia, Singapore.

- In East Asia: North Korea.

- In Oceania: Australia, New Zealand.

- In South America: Chile, Ecuador, Peru, Uruguay, Venezuela.

Among these 53 countries the "front runners" are Poland, Turkey, Vietnam, and Kazakhstan. However the plans of these countries are focused on LR.

\section{Nuclear Countries}

Nowadays 31 countries use nuclear power for electricity generation. The complete list is:

- In Europe: Belgium, Bulgaria, Czech Republic, Finland, France, Germany, Hungary, Netherlands, Romania, Slovakia, Slovenia, Spain, Sweden, Switzerland, Ukraine, United Kingdom.

- In Africa: South Africa.

- In western and northern Asia: Armenia, Iran, Russia.

- In central and southern Asia: India, Pakistan.

- In East Asia: China, Japan, South Korea, Taiwan.

- In North America: Canada, United States.

- In South America: Argentina, Brazil, Mexico.

\section{Second selection}

Several organizations state that nuclear energy will play a full part in the future energy mix. "Nuclear safety and transparency are continuously being reinforced and this will strengthen public acceptance" [12]. Many countries with existing nuclear power programs have plans to build new power reactors. In particular most of the reactors currently planned are in the Asian region, with fast-growing economies and rapidly rising electricity demand, typically China and India [13]. Few countries recently decided to close plants, other countries decided to abandon the use of nuclear energy completely and other countries put their plans on hold. In contrast, several countries (mostly developing countries) have re-affirmed their intentions to develop nuclear power as an important part of their energy mix supporting the idea that the Fukushima accident has not so far led to a significant retraction in nuclear power programmes [14] [12].

The impact of Fukushima accident on countries energy's policy is to be taken into account for the selection of the most interesting countries for the deployment of SMRs. Ten countries ${ }^{1}$ are involved in the research and in the development of SMRs. The strategic factor "Development of
SMR designs" wants to bring attention to the importance that the SMRs and their development have within a country; e.g. the US Department of Energy announced in March 2012 that a total of $\$ 450$ million would be available to support first-of-akind engineering, design certification and licensing of two SMRs [15]. This information is not sufficient to estimate if it is possible to install SMRs in these countries. Some countries are developing these new technologies in order to use them in their energy mix, while others (e.g. South Korea) mainly to export the technology to foreign countries with more favourable scenarios. Table 2 and Table 3 report a classification of the countries based on their interest level in the SMRs. Specific reports show a great interest in the use of SMRs in cogeneration, mainly for district heating and desalination. These twenty-one countries go to the next stage to determine the countries where SMRs are more profitable. Table 2 shows the non-selected countries clustered in two groups:

- Possible revaluation in long time horizon.

At the moment these countries are not interested in SMRs and they are inclined to build LRs, or they have not already outlined their energy policy regarding nuclear power (especially for the emerging nuclear energy countries). SMRs could be taken into consideration in long time horizon, in the case that:

- They demonstrate to be advantageous provoking changes in the energetic policies of the more uncertain countries.

- The LRs should not be built (wherever this plan is present) and then replaced with the SMRs.

- There are advantageous conditions for the SMRs, which involve their strength points and therefore they should not be left out.

- $\quad$ No interest in SMRs due to:

- no intention to build any nuclear power plants;

- $\quad$ intention to get out of the nuclear;

- no intention to expand the nuclear generation;

- actual nuclear expansion through LRs and no other plans of expansion to justify the introduction of SMRs.

\begin{tabular}{|c|c|c|}
\hline $\begin{array}{c}\text { Level of } \\
\text { interest }\end{array}$ & $\begin{array}{c}\mathbf{N}^{\circ} \text { of } \\
\text { countries }\end{array}$ & Countries \\
\hline $\begin{array}{c}\text { Possible } \\
\text { revaluation in } \\
\text { long time } \\
\text { horizon }\end{array}$ & 26 & $\begin{array}{c}\text { Armenia, Azerbaijan, Bangladesh, Canada, } \\
\text { Chile, Croatia, Japan, Jordan, Kenya, Latvia, } \\
\text { Lithuania, Namibia, Nigeria, Norway, Poland, } \\
\text { Romania, Senegal, Slovakia, South Africa, Sri } \\
\text { Lanka, Sudan, Taiwan, Thailand, Uganda, } \\
\text { Ukraine, Vietnam }\end{array}$ \\
\hline $\begin{array}{c}\text { Not interested } \\
\text { in SMRs. }\end{array}$ & 37 & $\begin{array}{c}\text { Albania, Algeria, Australia, Belarus, Belgium, } \\
\text { Bulgaria, Czech Republic, Ecuador, Egypt, } \\
\text { Finland, France, Georgia, Germany, Hungary, } \\
\text { Iran, Ireland, Israel, North Korea, Kuwait, } \\
\text { Libya, Malaysia, Netherlands, New Zealand, } \\
\text { Oman, Peru, Portugal, Serbia, Singapore, } \\
\text { Syria, Slovenia, Spain, Sweden, Switzerland, } \\
\text { Turkey, UAE, Venezuela, Yemen }\end{array}$ \\
\hline
\end{tabular}

Table 2 Non-selected countries

${ }^{1}$ Argentina, Canada, China, France, India, Japan, Russia, South Africa, South Korea, USA 
Table 3 shows the countries that have been selected for further analysis and thus they are countries where SMRs could be deployed.

\begin{tabular}{|c|c|c|}
\hline Level of interest & $\begin{array}{c}\mathrm{N}^{\circ} \text { of } \\
\text { countries }\end{array}$ & Countries \\
\hline $\begin{array}{l}\text { Declared intention to } \\
\text { introduce SMRs }\end{array}$ & 9 & $\begin{array}{c}\text { Argentina, China, Ghana, India, } \\
\text { Indonesia, Kazakhstan, Mongolia, } \\
\text { Russia, USA }\end{array}$ \\
\hline $\begin{array}{l}\text { Consider SMRs in } \\
\text { nuclear power } \\
\text { programme }\end{array}$ & 12 & $\begin{array}{l}\text { Brazil, Estonia, South Korea, } \\
\text { Mexico, Morocco, Pakistan }{ }^{2}, \\
\text { Philippines, Qatar, Saudi Arabia, } \\
\text { Tunisia, United Kingdom, Uruguay }\end{array}$ \\
\hline Total & 21 & \\
\hline
\end{tabular}

Table 3 Countries where SMRs could be deployed

\section{Third selection}

Table 3 summarises the results from the previous screening. The countries in this table are considered for subsequent analysis. The distinction between "Declared intention to introduce SMRs" and "Consider SMRs in nuclear power programme" may be useful to promote the countries with "Declared intention to introduce SMRs". This section deals with the third screening implementing the methodology proposed in Figure 1. First, SMR's strengths will be considered and then the strategic factors will be outlined. The literature review on SMR shows a great emphasis on simplification and its expected benefits, in order to make them competitive with alternate types of electricity or heat generation plants like LRs but also CCGT and coal power plants.

Competitiveness of SMRs strongly depends on the analysed scenarios. According to [16], [17] and [18] is wise to consider two different scenarios:

- on grid locations that have large interconnected electricity grids;

- off grid locations that are isolated or remote locations with small local electricity grids.

In off grid locations LRs encounter many limitations which do not allow them to compete in the energy market. Usually the size of each power plant must be less than $10 \%$ of the size of the grids to avoid problems in the overall grid management and stability. Niche markets need of technical and infrastructural requirements, specific climate, siting and transportation conditions, possibility of co-generation for heat or desalinated water. SMRs have all these requirements [19].

In some cases, SMRs are being developed in response to specific user requirements, mostly related to safety and cogeneration. The requirements issued in different countries have a number of common points [20] [21]:

- a simpler and more rugged design;

- standardization of the features that can be done in a factory environment with a reduction in the unit cost;

- long life times and time between refuelling;

- $\quad$ increased safety margins leading, for example, to longer periods before operator actions are needed to rectify abnormal situations;

\footnotetext{
${ }^{2}$ We remember that Pakistan is outside the Nuclear Non-Proliferation Treaty due to its weapons programme.
}

- lower risk of core damage;

- minor accident consequences for the population in the case of core damage.

SMRs seem to respond well to these requirements, because they allow for design simplification and for introduction of new features, such as passive components and processes that avoid the need for early action by the operator in an abnormal situation.

\section{Favourable factors for SMRs}

Factors that could favour a reasonably competitive SMR in energy markets include [20] [5]:

- a lower initial capital investment and correspondingly reduced investment risk;

- the ability to meet countries with low rates of increasing in the energy demand: plugging in to the grid SMRs instead LR over the years could better match the demand of new power plants;

- easier cogeneration opportunities;

- they are more appropriate for small electricity distribution grids, which are often found in small or developing countries, where they are good candidates for the replacement of older fossil-fuelled plants.

For example, in regions with a slow increase in electricity demand or for utilities with small distribution networks, SMRs may represent an interesting alternative. This aspect is particularly important for developing countries. From [19], [22], [23] and [5] we can summarize the following list of promoting factors of SMRs:

- smaller incremental capacity addition to match power demand and growth rate (scalability);

- domestic supply chain;

- low carbon energy source;

- $\quad$ reduced time-to-market and less uncertainty;

- $\quad$ enhanced safety and robustness from simplified designs;

- full factory fabrication;

- $\quad$ adaptable to a broader range of energy needs: electricity and heat;

- flexible siting;

- economy of subsequent factory fabricated units;

- reduced financial risks for investors

[24] presents further factors related to the resilience of SMR against extreme external events (see Table 4 ). Even these factors contribute to a greater siting flexible of the SMRs.

These benefits provide a competitive advantage to SMRs compared to LRs. All these factors make SMRs very suitable to be deployed in several scenarios. 


\begin{tabular}{|l|l|}
\hline Category & External event \\
\hline \multirow{5}{*}{ Natural events } & Earthquakes \\
\cline { 2 - 2 } & Extreme meteorological conditions \\
\cline { 2 - 2 } & Cyclones \\
\cline { 2 - 2 } & Floods \\
\cline { 2 - 2 } & Lightning \\
\cline { 2 - 2 } & Landslides and avalanches \\
\hline \multirow{5}{*}{$\begin{array}{l}\text { Additionan induced events } \\
\text { events }\end{array}$} & Aircraft crashes \\
\cline { 2 - 2 } & Explosions \\
\cline { 2 - 2 } & Electromagnetic interference \\
\cline { 2 - 2 } & $\begin{array}{l}\text { Fire generated from off-site sources (gas } \\
\text { production, smoke) }\end{array}$ \\
\hline
\end{tabular}

Table 4 External event taken into account in SMRs design [24]

\section{Unfavourable factors for SMRs}

In [20] the factors inhibiting the deployment of SMRs can be divided into technological and economic categories.

\section{Technological factors:}

- FOAK nature: implies the need to demonstrate the main new features and FOAK costs: The detailed design of the plant itself and development of manufacturing specifications, factory equipment, facilities, start-up, tooling, and setup of factories used for manufacturing specific equipment for the nuclear energy system.

- The multitude of similar designs currently being proposed results in a splitting of efforts and capital.

\section{Economic factors:}

- The economies of scale promote large reactors, which fit well into long-term programmes for countries with centralized energy supply and well-developed distribution networks.

- Differences in regulation systems among different countries often require various design changes, which increase the cost of developing SMRs.

- There is a lack of capital for development. The uncertainty of market conditions in the medium term favours investments in well-established technologies rather than in riskier $\mathrm{R} \& \mathrm{D}$ efforts.

- Heat generation faces additional problems. Nuclear heat is currently not cost-competitive with several fossil fuel technologies, and district heating is additionally burdened by the distribution costs.

\section{Strategic scenarios}

As previously anticipated the favourable and unfavourable factors for SMRs bring to the definition of 8 possible strategic scenarios. Each strategic scenario incorporates several specific sub-scenarios that characterize the environment in which SMRs could be deployed. Table 5 summaries the most relevant findings.

\begin{tabular}{|c|c|c|}
\hline & STRATEGIC SCENARIO & SUB SCENARIO \\
\hline \multirow{2}{*}{ A } & \multirow{2}{*}{$\begin{array}{l}\text { Countries with small and medium sized electricity grids and/or limited energy } \\
\text { demand growth }\end{array}$} & Smaller utilities with low capitalization \\
\hline & & Larger utilities with small load growth \\
\hline \multirow{2}{*}{ B } & \multirow{2}{*}{$\begin{array}{l}\text { Villages, towns and energy intensive industrial sites that are remote from } \\
\text { existing grids }\end{array}$} & Distributed or remote communities \\
\hline & & Units combine together as part of a large system \\
\hline \multirow{2}{*}{$\mathrm{C}$} & \multirow{2}{*}{ Rapidly growing area in developing countries } & Area with rapid energy demand growth \\
\hline & & Country with rapid economic growth \\
\hline \multirow{3}{*}{$\mathrm{D}$} & \multirow{3}{*}{ Non electrical power needs: by-product } & Desalinated water production \\
\hline & & District heating \\
\hline & & Industrial process heat \\
\hline \multirow{4}{*}{$\mathrm{E}$} & \multirow{4}{*}{ Flexible siting } & Reduced availability of water \\
\hline & & Deployment in seismic zones \\
\hline & & Flexible transport for their reduced dimension \\
\hline & & Very little ground space for the plant \\
\hline $\mathrm{F}$ & $\begin{array}{l}\text { Countries that are developing SMR design and that want to introduce them in } \\
\text { own energy mix }\end{array}$ & Deployment in own energy mix \\
\hline $\mathrm{G}$ & Countries which have nuclear power plants in their energy mix & Country having nuclear power plants \\
\hline \multirow{2}{*}{$\mathrm{H}$} & \multirow{2}{*}{ Presence in the Country of economic energy sources in competition with nuclear } & Non-renewable sources \\
\hline & & Renewable sources \\
\hline
\end{tabular}

Table 5 Scenarios analysis 


\section{RESULTS}

Table 6 shows the evaluation of the strategic scenarios for each country selected in the previous screening. We adopt the concept screening by [25]. This approach follows a six-step process which leads the decision maker through the selection activity.

The steps are:

1. Prepare the selection matrix: Country - Strategic scenario (columns from A to $\mathrm{H}$ ).

2. Rate the alternatives: $++,+, 0,-,--$.

3. Rank the alternatives: for each country sum the rate of the 8 strategic scenarios.

4. Combine and improve the alternatives.

5. Select one or more alternatives.

6. Reflect on the results and the process.

With this approach it is possible to define a relative ranking between the 21 countries, considering that the focus is to outline the main top countries where SMRs are more profitable.
It is important to emphasize that this study is directed to (1) compare SMRs and LRs and (2) SMRs with other technologies for the electricity production. The selected scenarios are aimed at determining the conditions in which the SMRs have a competitive advantage over the LRs and other base load power plants. In summary we aim to identify scenarios suitable for deploying SMRs.

In particular:

++ : Strategic scenario (j) is very important in the Country (i).

+: Strategic scenario (j) is present in the Country (i).

0 : Strategic scenario (j) is irrelevant in the Country (i).

-: Strategic scenario (j) is not present in the Country (i).

--: Strategic scenario (j) is negative in the Country (i).

In conclusions Table 6 crosses the countries selected in the previous screenings with the 8 scenarios $(\mathrm{A}-\mathrm{H})$ identified in Table 5. For each country/scenarios intersection identify the suitability for deploying SMR and then ranks the countries accordingly.

\begin{tabular}{|c|c|c|c|c|c|c|c|c|c|c|c|c|c|c|}
\hline & \multicolumn{14}{|c|}{ STRATEGIC SCENARIO } \\
\hline & Country & A & B & $\mathrm{C}$ & $\mathrm{D}$ & $\mathrm{E}$ & $\mathrm{F}$ & $\mathrm{G}$ & $\mathrm{H}$ & + & 0 & - & NET & RANK \\
\hline 1 & Argentina & - & + & + & + & 0 & + & + & 0 & 5 & 2 & 1 & 4 & 3 \\
\hline 2 & China & - & + & ++ & + & 0 & + & + & 0 & 6 & 2 & 1 & 5 & 2 \\
\hline 3 & Ghana & ++ & - & + & 0 & + & - & - & - & 4 & 2 & 4 & 0 & 6 \\
\hline 4 & India & - & + & ++ & + & + & + & + & 0 & 7 & 1 & 1 & 6 & 1 \\
\hline 5 & Indonesia & 0 & + & + & + & ++ & - & - & 0 & 5 & 2 & 2 & 3 & 4 \\
\hline 6 & Kazakhstan & 0 & + & + & + & + & - & - & + & 5 & 1 & 2 & 3 & 4 \\
\hline 7 & Mongolia & + & 0 & ++ & 0 & + & - & - & + & 5 & 2 & 2 & 3 & 4 \\
\hline 8 & Russia & - & ++ & - & + & + & + & + & 0 & 6 & 1 & 2 & 4 & 3 \\
\hline 9 & USA & - & ++ & - & + & 0 & ++ & + & 0 & 6 & 2 & 2 & 4 & 3 \\
\hline 10 & Brazil & - & + & 0 & 0 & 0 & - & + & 0 & 2 & 4 & 2 & 0 & 6 \\
\hline 11 & Estonia & + & - & + & + & -- & - & - & 0 & 3 & 1 & 5 & -2 & 8 \\
\hline 12 & Mexico & - & - & - & + & 0 & - & + & - & 2 & 1 & 5 & -3 & 9 \\
\hline 13 & Morocco & + & 0 & - & + & + & - & - & 0 & 3 & 2 & 3 & 0 & 6 \\
\hline 14 & Pakistan & 0 & 0 & 0 & + & + & - & + & 0 & 3 & 4 & 1 & 2 & 5 \\
\hline 15 & Philippines & + & - & 0 & 0 & + & - & - & 0 & 2 & 3 & 3 & -1 & 7 \\
\hline 16 & Qatar & + & 0 & ++ & + & + & - & - & - & 5 & 1 & 3 & 2 & 5 \\
\hline 17 & Saudi Arabia & - & ++ & 0 & + & + & - & - & - & 4 & 1 & 4 & 0 & 6 \\
\hline 18 & South Korea & - & + & - & + & + & 0 & + & 0 & 4 & 2 & 2 & 2 & 5 \\
\hline 19 & Tunisia & + & 0 & -- & + & + & - & - & 0 & 3 & 2 & 4 & -1 & 7 \\
\hline 20 & United Kingdom & - & - & -- & + & -- & - & + & 0 & 2 & 1 & 7 & -5 & 10 \\
\hline 21 & Uruguay & + & 0 & 0 & 0 & - & - & - & 0 & 1 & 4 & 3 & -2 & 8 \\
\hline
\end{tabular}

\section{DISCUSSION}

Strategic scenario A [Countries with small and medium sized electricity grids and/or limited energy demand growth]: the judgment ++ has been assigned only to Ghana because among the 21 selected countries, Ghana is the only one with the following criteria:

- $\quad$ smaller utilities with low capitalization;

- distributed or remote communities.
The utilities have not to be too small because they have to guarantee the SMRs deployment and operation. SMR can be deployed even if a country has not this scenario, so the judgment - - is not assigned.

Strategic scenario B [Villages, towns and energy intensive industrial sites that are remote from existing grids]: the judgment ++ has been assigned to Russia, USA and Saudi Arabia. The considerable extension of the first two countries and the presence of the deserts, make it possible to find many isolated centres that require energy, even in considerable 
quantities and in a quite stable way, or in a rapidly evolving situation. This means that the SMRs are suitable for a small market size as well as to follow the grow of demand with a staged deployment.

The applicable scenarios are:

- distributed or remote communities:

- $\quad$ units combined together as part of a large system;

- larger utilities with small load growth.

For this strategic scenario there are no judgments - - because, like in the previous point, the absence of such criteria in a country does not make it necessary to judge them in negative way.

Strategic scenario C [Rapidly growing area in developing countries]: this is the scenario that most contributes to the final rank, with China, India, Mongolia and Qatar have judgment + + while Tunisia and United Kingdom have - - . In this strategic scenario are associated the following criteria:

- $\quad$ areas with rapid energy demand growth;

- country with rapid economic growth.

The rating ++ has been assigned to those countries that have high rates of growth in both factors. On the contrary, the judgment - - has been assigned to those which occupy the last positions. In this way is possible to take into account a very important feature for investments of such importance that are difficult to place in countries with low growth rates both economic and energetic.

Strategic scenario D [Non electrical power needs: byproduct]: has not been associated with any "critical" judgment. The reason lies in the fact that despite the by-products for the SMRs are now highly regarded worldwide, few feasibility studies have been carried out to evaluate the economics of SMRs and desalination systems or district heating ${ }^{3}$. So there is not a single country that is focusing predominantly on the byproducts to deserve $\mathrm{a}++$ rating. On the opposite side we cannot state that is a negative factor for a country to associate -or -. There is a growing interest in co-generation that can bring significant environmental and economic advantages. The range of judgments is + for the countries that want to deploy byproduct systems and 0 for those that don't consider the option.

Strategic scenario E [Flexible siting]: this scenario is crucial for Indonesia, where all criteria are met:

- reduced availability of fresh water;

- deployment in seismic zones;

- flexible transport for their reduced dimension;

- $\quad$ very little ground space for the plant.

The judgment ++ has been given only to Indonesia, while + has been given to many others countries because it is possible to find many scenarios in which these criteria are present but not all together. Where the factors are totally absent, it can be said that there is an obstacle to the profitability of the SMRs since they are one of SMRs' main strengths. At this point to Estonia and United Kingdom has been assigned - -.
Strategic scenario $F$ [Countries that are developing SMR design and that want to introduce them in own energy mix]: the judgment ++ has been assigned only to the USA because is the country developing the largest number of new designs and allocating substantial funding for the SMR development. In the USA, the total funding is expected to provide a total investment of about $\$ 900$ million [26]. Worthy of note is the judgment awarded to South Korea: 0. This country is developing new designs for SMRs, but this is not an important scenario because its intentions are to export this technology in developing countries rather than install them on its territory [27] [28].

Strategic scenario $G$ [Countries which have nuclear power plants in their energy mix]: has not been associated with any "critical" judgment. The only ratings assigned are + and -. The first has been given to those countries already having nuclear power plants and the second in those countries that have not yet it but, for the results of the first and second screening, have shown interest in introducing this technology. Obviously, the judgment - represents the difficulty for a new country to join the nuclear market, with significant cost on the one hand and stringent certification requirements on the other hand. The beginning of a nuclear power programme involves several complex and interrelated activities with long duration. Experience shows that the time between an initial policy decision by a state to consider nuclear power up to the start of operation of its first nuclear power plant will be at least 10-15 years. This period consists of three major phases [29]:

1. considerations before a decision to launch a nuclear power programme is taken;

2. preparatory work for the construction of an NPP after a policy decision has been taken;

3. activities to implement a first NPP.

Strategic scenario H [Presence in the Country of economic energy sources in competition with nuclear]: has not been associated with any "critical" judgment. Many judgments are 0 , and they have been assigned to those countries having all the reserves sources as coal, oil, natural gas and uranium and also to those countries which have no one reserves. Kazakhstan and Mongolia have obtained + . Kazakhstan is a rich country in all the energy sources especially uranium, is the second largest country with uranium reserves (behind Australia). Mongolia has no considerable reserves except a discrete amount of uranium. Saudi Arabia, Qatar and Ghana have evaluation especially because the first two have great reserves of oil and natural gas and Ghana authorities have reported that it was discovered in 2007 an oilfield of 2 billion barrels. For these countries the most reasonable choice would be to exploit oil and natural gas, such as they are already doing, rather than enter into the nuclear market which would entail very high costs.

\footnotetext{
${ }^{3}$ The main studies are [31], [32], [33], [34]
} 


\section{CONCLUSIONS}

The aim of the paper is to identify scenarios and countries suitable for the development of SMRs; predominantly from the perspective of investors and policy makers. SMRs are a relatively "new product" in the nuclear industry since they are not a scaled version of more traditional LRs, but a new concept on nuclear power plant. SMRs aim to take advantage of a smaller size to implement new technical solutions and easier construction. SMRs intend to exploit the "economy of multiples" rather than the "economy of scale". The more suitable scenarios for deployments of SMR are: countries with areas with small and medium sized electricity grids and/or limited energy demand growth, Villages, towns and energy intensive industrial sites that are remote from existing grids, rapidly growing area in developing countries, non electrical power needs: by-product, flexible siting, countries that are developing SMR design and that want to introduce them in own energy mix, countries which have nuclear power plants in their energy mix, presence in the country of economic energy sources in competition with nuclear. The countries having this scenarios and therefore more suitable for the short-term deployment of SMR are India, China, Argentina, Russia, USA, Indonesia, Kazakhstan, Mongolia, Pakistan, Qatar, South Korea.

\section{REFERENCES}

[1] IAEA, "Energy, electricity and nuclear power: developments and projections - 25 years past and future," Vienna, 2007.

[2] Giorgio Locatelli and Mauro Mancini, "Sustainability in the power plant choice," International Journal of Business Innovation and Research, vol. 7, no. 2, pp. 209-227, 2013.

[3] IAEA, "International Status and Prospects of Nuclear Power," Vienna, 2010.

[4] WNA. (2012, March) World Nuclear Association. http://www.world-nuclear.org/info/inf33.html.

[5] Vladimir Kuznetsov and Aexey Lokhov, "Current status, technical feasibility and economics of small nuclear reactors," Nuclear energy agency Organisation of economic cooperation and development, Paris, 2011.

[6] Inkeri Ruuska, Tuomas Ahola, Karlos Artto, Giorgio Locatelli, and Mauro Mancini, "new governance approach for multi-firm projects: Lessons from Olkiluoto 3 and Flamanville 3 nuclear power plant projects," International Journal of Project Management, vol. 29, no. 6, pp. 647-660, 2011.
[7] Giorgio Locatelli and Mauro Mancini, "Looking back to see the future: Building nuclear power plants in Europe," Construction Management and Economics , vol. 30, no. 8, pp. 623-637, 2012.

[8] IAEA. (2012, September) International Atomic Energy Agency. http://pris.iaea.org/public/

[9] WNA. (2012) World Nuclear Association. http://www.world-nuclear.org/info/reactors.html

[10] United Nations. (2006, July) United Nations. http://www.un.org/en/members/index.shtml

[11] WNA. (2012, February) Emerging Nuclear Energy Countries. http://www.worldnuclear.org/info/inf102.html

[12] WEC, "World Energy Perspective: Nuclear Energy One Year After Fukushima," World Energy Council, London, 2012.

[13] WNA. (2012, February) World Nuclear Association. http://www.world-nuclear.org/info/inf17.html

[14] AREVA, Impact of Fukushima event on nuclear power sector, March 25, 2011.

[15] WNN. (2012, May) World Nuclear News. http://www.world-nuclear-news.org/NN-

SMR_vendors_apply_for_government_funds2205124.html

[16] Giorgio Locatelli and Mauro Mancini, "Small-medium sized nuclear coal and gas power plant: A probabilistic analysis of their financial performances and influence of CO2 cost," Energy Policy, vol. 10, no. 38, pp. 63606374, 2010 .

[17] Giorgio Locatelli and Mauro Mancini, "Large and small baseload power plants: Drivers to define the optimal portfolios," Energy Policy, vol. 39, no. 12, pp. 7762$7775,2011$.

[18] S Boarin, G Locatelli, M Mancini, and M E Ricotti, "Financial case studies on small- and medium-size modular reactors," Nuclear Technology, vol. 178, no. 2, pp. 218-232, 2012.

[19] Daniel Ingersoll, Small Modular Reactors and the Nuclear Renaissance, March 31, 2011.

[20] OECD/NEA. (2008) NEA Nuclear Energy Agency. http://www.oecd-nea.org/brief/brief-07.html 
[21] NuScale Power, Technology Overview \&

Commercialization Update, November 2010.

[22] Giorgio Locatelli and Mauro Mancini, "The role of the reactor size for an investment in the nuclear sector: an evaluation of not-financial parameters," Progress in Nuclear Energy, vol. 53, no. 2, pp. 212-222, 2010.

[23] Mario D. Carelli et al., "Economic features of integral, modular, small-to-medium size reactors," Progress in Nuclear Energy, vol. 52, no. 4, 2010, pp. 403 - 4141.

[24] Vladimir Kuznetsov, Advanced Nuclear Plant Design Options to Cope with External Events, August 2007.

[25] Karl T. Ulrich and Steven D. Eppinger, "Concept selection," in Product Design and Development, 5th ed. Philadelphia: McGraw-Hill / Irwin, 2012, vol. 1, ch. Chapter 8, pp. 145-161.

[26] WNN. (2012, April) world nuclear news. http://www.world-nuclear-news.org/NNNew_US_partnership_for_SMR_development2004127.html

[27] KAERI. (2012, July) SMART. http://smart.kaeri.re.kr/pages/view/41/cooper

[28] WNA. (2012, March) World Nuclear Association. http://www.world-nuclear.org/info/inf81.html

[29] IAEA, "Considerations to Launch a Nuclear Power Programme," Vienna, Austria, 2007.

[30] B. M. Misra and J. Kupitz, "The role of nuclear desalination in meeting the potable water needs in water scarce areas in the next decades," IAEA, Vienna, 2004.

[31] S. Nisan and S. Dardour, "Economic evaluation of nuclear desalination systems," European Desalination Society and University of Montpellier II, 2006.

[32] Ibrahim Khamis and Vladimir Anastasov, "Environmental impacts and implications for planning and monitoring activities," Journal of Environmental Monitoring, vol. 12, no. 1/2010, pp. 50-57, January 2010.

[33] CNNC, The Coupling of Desalination Plant and PWR Nuclear Power Plant, July 14, 2010. 